\title{
Perceptual Deficits in Clumsy Children: Inter- and Intra-modal Matching Approach-A Window into Clumsy Behavior
}

\author{
H. Sigmundsson \\ Research Group for Child Development, Norwegian University of Science and Technology, \\ Trondheim, Norway; Department of Psychology, Umeå University, Umeå, Sweden
}

\begin{abstract}
This article will focus on the underlying perceptual deficits that might lead to inadequacies in motor performance in children. Two lines of enquiry have dominated the literature: visual-perceptual deficit and/or visualmotor deficits and proprioceptive deficits. The theoretical and methodological shortcomings in these approaches are discussed. Then attention is primarily directed toward the concept of inter- and intra-modal matching (sensory integration), particularly with respect to vision and proprioception, an ability deemed to underlie many real-life motor skills. Such an approach allows parallels to be drawn between behavioral manifestations of motor impairment and potential underlying neurological informationprocessing disorders, particularly as these relate to hemispheric competence.
\end{abstract}

\section{KEYWORDS}

perceptual information, inter-/intra-modal, intra- $/$ inter-hemsipheric processing; lateralization

Reprint requests to: H. Sigmundsson, Research Group for Child Development, Norwegian University of Science and Technology, Trondheim, Norway;

e-mail: hermundurs@svt.ntnu.no

\section{INTRODUCTION}

\section{Definitions and Etiology}

The possibility that the neural factor in many cases of motor impairment may stem from circumstances other than those of brain damage has remained relatively unexplored. As a result of this situation, a child with obvious difficulties in skill learning may not be recognized as being impaired because of the failure of any test of brain damage to identify the cause (Morris \& Whiting, 1971, p. 155).

Nearly 30 years after this statement was made, a review of the literature will confirm that attempts to explore its implications have been few and far between. Where this has happened, researchers have been wary of elaborating upon, or delving too deeply into, possible nomological networks. This paper is a step towards redressing that imbalance, its departure point being that neuropsychological factors may figure more prominently in explanations of motor impairment than has been appreciated.

Some reasons for this apparent neglect can be attributed to the fact that the concept of motor impairment is both diffuse and ill defined. Attempts to refine definitions to distinguish the phenomenon from extant disease entities may, it is suggested here, have resulted in throwing out the baby with the bath water. Motor impairment is a concept that has been discussed in the literature for at least 75 years (for example, Orton, 1937; Walton et al., 1962; Morris \& Whiting, 1971; Gubbay, 1975; 
Gordon \& McKinley, 1980; Henderson \& Hall, 1982; Sigmundsson \& Whiting, 2002) at which time the Russian Oseretsky (1923) from the Psychoneurological Clinic in Moscow, rather significantly, was developing tests designed to aid in broad diagnoses of neurological and motor deficiency. As a behavioral phenomenon, however, motor impairment must have been observed since time immemorial, much to the frustration of both parents and members of the medical profession confronted by children exhibiting the syndrome.

\section{Prevalence and Characteristics}

Most recent definitions of motor impairment invoke the concept of norms although it would generally be accepted that they are difficult both to quantify and to establish, particularly in the absence of any clear consensus about what is normal development. Despite these difficulties, various estimates of the prevalence of the syndrome have been put forward on the basis of the results of a number of different standardized tests. These estimates have ranged from $5 \%$ to $10 \%$ when limited to children in the age range 5 to 12 years (see for example, Brenner et al., 1967; Gubbay, 1975; Henderson \& Hall, 1982; Mæland, 1992; American Psychological Association, 1994). Mæland's (1992; Søvik \& Mæland, 1986) 6\% estimate, based on the use of standardized tests, of the number of school-age children in Norway manifesting the motor impairment syndrome is very similar to estimates made in other countries (Brenner et al., 1967; Gubbay, 1975; Henderson \& Hall, 1982) when similar criteria have been invoked. Most prevalence studies report a much higher incidence of motor impairment in boys than in girls (Gubbay, 1978; Henderson \& Hall, 1982; Keogh et al., 1979; Mæland, 1992).

The importance of recognizing the syndrome and not dismissing it 'as within the norm' is that difficulties experienced by the motor-impaired child can be expected to have a knock-on effect in a wide range of skills-motor, social, linguistic, and so on. Note, for example, that $2 \%$ to $10 \%$ of children of similar age groups have been reported to have a variety of language problems, manifested in speech, reading and writing (Rutter, 1978; Stevenson, 1984; Gaddes, 1985; Stein, 1994; American Psychological Association, 1994). Perhaps more noteworthy in the present context is a reported overlap of between $40 \%$ and $70 \%$ in the number of children exhibiting both motor and language impairments (Paul et al., 1983; Wolff et al., 1995; Rintala et al., 1998; Nickisch, 1998; Estil et al., 2003). The suggestion that this overlap is unlikely to be fortuitous led Estil and Whiting (2002) to explore whether, when language and motor impairments occur together, the relation is direct or indirect. The notion of a direct relation would imply that both kinds of impairment are simply different manifestations of one underlying substrate, for example, a poorly developed or dysfunctional neurological system. An indirect relation, in contrast, would imply that there is one primary problem - either motor or language - and that the secondary related problem - either language or motor-arises as a consequence of social constraints to which the primary problem gives rise.

Given such a broad-based syndrome it is not surprising that there should be universal agreement that motor-impaired children do not constitute a homogeneous group (Søvik \& Mæland, 1986; Sigmundsson et al., 1997a) although the tendency in the literature has been to do just that. That this may be an unfortunate omission is attested to by Dodd et al., (1989) albeit in the context of language impairment-who report that the different patterns of performance of their groups on different experimental tasks supports the notion that subgroups are relatively distinct and that their different surface production errors reflect different underlying deficits. If the implications of this 
statement are not accepted, then the methods of intervention provided for non-specified groups of motor impaired children can be only of a very general kind. More specific forms of intervention must, therefore, await the establishment of acceptable criteria for delineating sub-groups and more in-depth knowledge of the reasons underlying the impairment.

\section{PERCEPTUAL DEFICITS IN MOTOR-IMPAIRED CHILDREN}

One attempt to go beyond the level of description with respect to putative factors underlying motor impairment has been that of ability testing. Following on the distinction made by Fleishman (1966) between skill and ability, there has been a noticeable attempt on the part of both experimental and developmental psychologists to explore the nature of underlying perceptual deficits that might lead to inadequacies in motor, language and social performance in children.

Two particular perceptual modes, perhaps not surprisingly, have attracted most attention, namely, the visual (Gubbay et al., 1965; Dare \& Gordon, 1970; Henderson \& Hall, 1982; Hulme et al., 1982a; Hulme, et al., 1982b; Hulme et al., 1984; Hulme \& Lord, 1986; Powell \& Bishop, 1992) and the proprioceptive' (Bairstow \& Laszlo, 1981; Laszlo \& Bairstow, 1985; Laszlo et al., 1988; Smyth, 1991; 1994).

\section{Theoretical problems}

Although these explorations have provided much useful information and triggered a number of new research paradigms, the theoretical and

\footnotetext{
'Proprioception: those receptor mechanisms, most noticeably in the joints, muscles and tendons. that signal information about the posture and movements of the body as a whole (Sherrington, 1906)
}

methodological frameworks in which they have been couched have limited their impact. As a consequence, there has been little consensus as to the causal agencies underlying such putative deficiencies in the form, for example, of neurological lag or impairment (for example, Hulme et al., 1982a,b; 1984; Hulme \& Lord, 1986; Laszlo \& Bairstow, 1985; Laszlo et al., 1988; Laszlo, 1990; Laszlo \& Sainsbury, 1993; Smyth, 1991; 1994).

With respect to visual-perceptual deficits, Hulme et al., (1982a; 1984), using a task of linelength matching within or between the modalities of vision and proprioception, and Hulme and Lord (1986) concluded that for many children their 'clumsiness' stems from a difficulty in processing visual information (for example, size consistency; visual discrimination). Unfortunately, the authors did not explore the nature of the putative 'visual deficits'. Did the problem reside in the sense organs, the visual perceptual system, decisionmaking based on limited visual information, a deficient effector system or combinations of all these?

Other researchers have focused on deficiencies in proprioceptive sensitivity and its role in relation to impaired perceptuo-motor performance (Laszlo \& Bairstow, 1985; Laszlo et al., 1988). These investigators used a task that required children to discriminate (proprioceptively without vision) the heights of two inclined runways. Interesting as their findings are, they take no account of a possible lateralization effect, which, as will be suggested below, may be an important factor in relation to causality. An extension to their explanatory framework on the basis of, for example, literature in which neurological lesion/disconnection has been linked to apraxia (see for a review Heilman \& Rothi, 1993) might have raised a number of important research questions. 


\section{Methodological and analytical problems}

Despite this limitation, the visual perceptual deficits hypothesis of Hulme and his colleagues (Hulme et al., 1982a,b; 1984; Hulme \& Lord, 1986), justified only by correlational studies, is less well supported by experimental findings than the proprioceptive deficits hypothesis put forward by Laszlo and her colleagues (Laszlo \& Bairstow, 1985; Laszlo et al., 1988). Be that as it may, Doyle et al. (1986) also questioned their use of the constant stimuli methodology, particularly the failure to take cognizance of the constraints associated with this procedure, namely, the values of the stimuli relative to the threshold and the number of observations made at each value (Sigmundsson et al., 2000). Furthermore, Elliott et al. (1988) and Sugden and Wann (1988) presented data inconsistent with the findings of Hulme and coworkers.

Despite these critical standpoints, this approach and attempts to determine underlying causal factors proved sufficiently challenging to justify exploring the concept of perceptual deficit further, albeit from a different perspective. It has long been recognized that to carry out coordinative actions in an affective way, close integration of information stemming from both inter and intra sensory systems is necessary:

In most cases of manual behavior, both vision and proprioception will affect the outcomes of manual movements. In fact, if such movements are to be smooth and well coordinated, it is of crucial importance that visual and proprioceptive means of controlling them are in correspondence. This implies that the parameters of space defined by each of these systems are in fine agreement. If both hands are involved in an act, it is also important that the proprioceptive space defined by one limb is in correspondence with the proprioceptive space defined by the other limb (Hofsten \& Rösblad, p.806).

Lee et al., (1990) supported this standpoint, arguing that this linking of information (inter- and intra-modal) is crucial to the development and to the maintenance of motor competence. That inter (visual space-proprioceptive space) and intra (proprioceptive space-proprioceptive space) modal matching might provide insight into the nature of the motor impairment syndrome was proposed, initially, in an investigation (unpublished) carried out by Jongmans (1989) and cited in Henderson (1993). Using a paradigm that Hofsten and Rösblad (1988) originally used with normal children, Jongmans investigated the performance of children exhibiting clumsy behavior required to perform a manual matching task to locate a target in which the availability of vision and proprioception were systematically manipulated. Matching the located target was always carried out without vision. Given that the movements required were minimal, success on the task depended to a large extent on the ability to match visual/proprioceptive and proprioceptive information in locating targets. The results showed that while the target remained visible, the motorimpaired group performed as accurately as their control peers. Moreover, the addition of proprioceptive information in locating the target did not improve the performance of either group. When only proprioceptive information about target location was available, however, both groups were less accurate, but the decrease for the motorimpaired group was much more striking (Henderson, 1993). This kind of finding led Sigmundsson and co-workers, beginning in 1997, to instigate a series of studies on motor impaired children in which the methodology of inter-modal and intra-modal sensory matching was used. The idea was to explore putative neurological explanations of motor impairment more intensively.

\section{PUTATIVE NEUROLOGICAL DISORDER IN HECP CHILDREN}

In the following studies, cognizant of the problems involved if distinctions are not made 
between sub-groups of children manifesting the motor impairment syndrome, more clearly defined sub-groups were selected, namely, those exhibiting hand-eye co-ordination problems (HECP). For this purpose the Movement $\mathrm{ABC}$ test (Henderson \& Sugden, 1992) was used, the children being ranked on the basis of their summed scores on the five hand-eye co-ordination subtests-throwing a bean bag, following a flower trail, playing bounce and catch, placing pegs, threading a lace. The HECP sample used in Sigmundsson et al. (1997a, b) and Sigmundsson (1999) had hand-eye co-ordination sub test scores of 11.3 on the $A B C$ test and the sample used in Sigmundsson et al., (1999) had scores of 11.62. Test procedures developed in the authors' laboratory for this purpose, in contrast to those that focus only on surface behavior, have been directed towards those sensory integration abilities deemed to underlie the way in which these children carry out a range of everyday motor tasks (Laszlo \& Bairstow, 1985; Hofsten \& Rösblad, 1988; Rösblad \& Hofsten, 1992; Lee et al., 1990; 1997). In this way it has been possible to draw parallels between behavioral manifestations of 'clumsiness' and possible underlying neurological information-processing disorders, particularly as these relate to hemispheric competence. This research was facilitated by the elaboration of an earlier developed testing instrument for sensory integration (Sandstrøm, 1953; Sandstrøm \& Lundberg, 1956; Hofsten \& Rösblad, 1988).

\section{Sensory integration tests}

\section{Manual matching task: 'Inter-and intra-modal} matching. Basically, the testing procedures require the sensory matching of targets located visually (seen target), with the hand (felt target) or in combination (felt and seen). Matching of the position of located targets is normally carried out without vision-an exception being the Sigmundsson (1999) study.
Studies carried out using sensory matching testing procedures (see Table 1) (Sigmundsson et al., 1997a,b; Sigmundsson, 1999) produced evidence of significant differences in inter- and intra-modal matching between right-handed HECP and normal children (age ranges 5 to 8 years) when combined scores for both hands were analyzed. The analysis of scores achieved with the right and left hand separately, however, demonstrated that the differences between the HECP and the control children could, in the main, be attributed to lowered performances when the left hand (nonpreferred hand) was used for matching the located target position. Further, intra-group analyses of the HECP children produced evidence of significant asymmetrical differences in intra- modal matching when the children were required to locate targets with the right hand and match the located target's position with the left hand compared to the condition in which they were required to locate with the left hand and match with the right hand. The performance in the latter condition was superior.

When the HECP children were required to use the left hand (right hemisphere mediation) to match the located target, their respective error scores under the visual as compared to the proprioceptive condition were $20 \mathrm{~mm}$ and $36 \mathrm{~mm}$. The control children in this respect had $14 \mathrm{~mm}$ and $24 \mathrm{~mm}$ in error scores (see Fig. 1). When using the right hand (left hemisphere mediation) to match the located targets, however, the respective error scores of the HECP children under the visual, as compared to the proprioceptive condition, were $22 \mathrm{~mm}$ and $25 \mathrm{~mm}$. The error scores of the control children were $14 \mathrm{~mm}$ and $22 \mathrm{~mm}$. These findings strongly suggest that the HECP children have input/planning problems when they are made dependent upon proprioceptive information picked up via the right hand (Sigmundsson et al., 1999a). The findings also clearly indicate the problem that the HECP children have compared with the control 


\section{TABLE 1}

Overview of studies on inter-and intra-modal matching by 7-and 8-year old children diagnosed as having hand-eye co-ordination problems (HECP) and by a control group of children without such problems.

\begin{tabular}{|l|l|l|l|l|}
\hline \multicolumn{1}{|c|}{ STUDY } & \multicolumn{1}{|c|}{ INPUT } & \multicolumn{1}{|c|}{ OUTPUT } & P * & $\begin{array}{l}\text { POSSIBLE EXPLANATIONS OF } \\
\text { THE DIFFERENCES }\end{array}$ \\
\hline Sigmundsson et al.1997a,b & $\begin{array}{l}\text { Vision } \\
\text { Vision }\end{array}$ & $\begin{array}{l}\text { right hand } \\
\text { left hand }\end{array}$ & $\begin{array}{l}\text { s (mean AE) } \\
\text { s (mean AE) }\end{array}$ & $\begin{array}{l}\text { visual-perceptual and/or visual- } \\
\text { motor deficits }\end{array}$ \\
\hline Sigmundsson et al.1997a,b & $\begin{array}{l}\text { Vision/right } \\
\text { hand }\end{array}$ & left hand & s (mean AE) & $\begin{array}{l}\text { visual-perceptual and/or visual- } \\
\text { motor deficits, } \\
\text { problem which modality to rely on }\end{array}$ \\
\hline $\begin{array}{l}\text { Sigmundsson et al.1997a,b } \\
\text { Sigmundsson et al.1997a,b } \\
\text { Sigmundsson, et al.1999 }\end{array}$ & $\begin{array}{l}\text { Right hand } \\
\text { Right hand } \\
\text { Right foot }\end{array}$ & $\begin{array}{l}\text { left hand } \\
\text { vision/left hand } \\
\text { left hand }\end{array}$ & $\begin{array}{l}\text { s (mean AE) } \\
\text { s (mean AE) }\end{array}$ & $\begin{array}{l}\text { right hemisphere insufficiency with } \\
\text { or without dysfunctional } \\
\text { callosum }\end{array}$ \\
\hline $\begin{array}{l}\text { Sigmundsson et al.1997a,b } \\
\text { Sigmundsson, 1999 }\end{array}$ & $\begin{array}{l}\text { Left hand } \\
\text { Left hand }\end{array}$ & $\begin{array}{l}\text { right hand } \\
\text { vision/right hand }\end{array}$ & $\begin{array}{l}\text { ns } \\
\text { ns }\end{array}$ & right hand \\
\hline Sigmundsson et al.1999 & Left foot & right hand & s (mean VE) & $\begin{array}{l}\text { right hemisphere insufficiency with } \\
\text { or without dysfunctional corpus } \\
\text { callosum }\end{array}$ \\
\hline Sigmundsson et al.1999 & Left foot & left hand & s (mean VE) & \begin{tabular}{l} 
right hemisphere insufficiency \\
\hline
\end{tabular}
\end{tabular}

*significant (s) differences between the HECP** and the control group of children on the mean absolute error (AE) score and mean variable error (VE) score (within subject variability).

${ }^{* *}$ In order to ensure that the findings were not the consequence of a particular selection of subjects, two different samples of HECP and controls were selected.

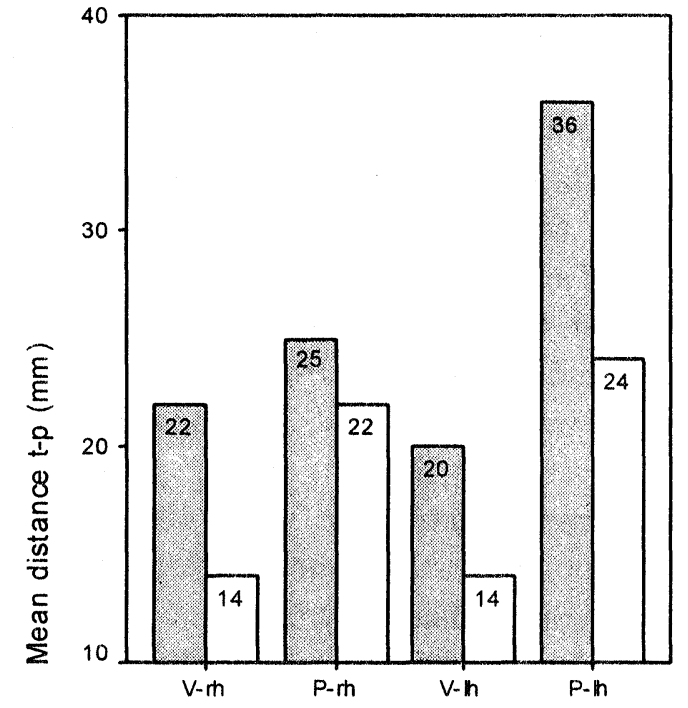

Condition
Fig. 1: Mean distance target-pin ( $t-p ;$ millimetres) scores for the two conditions of the experiment for hand-eye co-ordination problem (HECP) and control groups matching with the right hand $(\mathrm{rh})$ and the left hand (lh) ( $\mathrm{V}$ vision only; $\mathrm{P}$ propriocpetive only)

Legend: HECP $\square$ Control 
children in the inter-modal condition, namely, when the targets are located under visual control. Sigmundsson et al. (2002) followed up this possible 'visual deficit' and found that clumsy children have a problem regarding visuat processing, namely, they can have impaired visual sensitivity in both the dorsal and ventral streams.

2. HEMI-task: 'Toe-hand' matching. This task, in principle, provides the possibility to distinguish between intra- and inter-hemispheric competences in 'on-line' (namely, no proprioceptive/ tactile memory trace (off-line) is involved) target location-matching. Using the foot rather than the hand to locate targets allows the possibility of examining performance when the information processing involved is within hemispheres as well as between hemispheres (a possibility that is not afforded when the hand is used for location and the other hand for matching) (Sigmundsson et al., 1999a). Such a procedure, it was thought, might provide a window into information processing in the brain. The findings from a study (Sigmundsson et al., 1999a) carried out on a different group of 7 year-old right-handed HECP children showed that they did manifest inferior performance to the control children in 3 of 4 conditions where the right hemisphere was involved and/or information had to be transported across the corpus callosum (Table 1).

The left hand-right hemisphere problems shown (Table 1) are clearly not a feature of normal development and may therefore indicate a putative neurological abnormality. Invoking the hypothesis of Sperry (1974), Bogen $(1990 ; 1993)$, and Waal et al. (2000) about hemispheric specialization, these findings could be accounted for by right hemispheric insufficiency (lesion/disconnection) (Geschwind, 1975; Faglioni \& Basso, 1985; Heilman \& Rothi, 1993) with or without a dysfunctional corpus callosum which, in turn, might be attributable to slow maturation (Yakolev \& Lecours, 1967; Trevarthen, 1974; Galin et al., 1977; O'Leary, 1980; Quinn \& Geffen, 1986) or an interruption of transcallosal interhemispheric communication - the so-called 'callosal concept' of Bogen (1993). If these findings and theoretical interpretation should prove to be generalizable, then it would be expected that left-handed HECP children, in contrast, would be likely to have particular problems when using their right hand to match the position of the located targets. This was exactly what Sigmundsson \& Whiting (2002) found in a further study, thus, providing further support and extending the suggestion that the problems of HECP children, when compared with control peers, manifest themselves more clearly when they are required to use their nonpreferred hand.

The findings from Sigmundson (1999), in which the real-life skills of 'threading nuts onto a bolt' and 'threading beads' were the paradigm tasks, support these interpretations. These and similar tests have long been used in the literature and, more recently, have been developed by Henderson and Sugden (1992) and form part of their well-known Movement ABC test battery. In the Sigmundson study the focus was on 8-year-old right-handed HECP children and a control group.

\section{Visual-motor task}

'Threading beads'-task. 'Threading beads' is a bimanual task (the hands coordinate in performing separate aspects of the same task) demanding interhemispheric transfer of information for its successful performance, namely continuous use of feed forward as well as feedback information about component movements (Kalat, 1995; Jeeves, 1990). The significant differences shown between HECP and control children could provide further support for a dysfunctional corpus callosum, however, in the light of the difficulty already addressed in locating function it has to be appreciated that these findings could also be a consequence of right hemisphere insufficiency (for review see Banich, 1995). 
'Threading nuts on bolt'. In the $\mathrm{ABC}$ test battery, from which this test is taken, children are required to hold the bolt with their non-preferred hand and provide the action with their preferred hand. By adding a second condition in which the function of the two hands was reversed, it was possible to provide findings much more relevant to the question on hand. The finding of significant differences on this task between the HECP and the control children (aged 8 years) when the left hand (non-preferred hand) was used for screwing the nuts on supports the proposition that the HECP children have, mainly, a left hand (right hemispheric) competence problem (Sigmundsson, 1999). Remember, however, that the 'threading nuts on bolt' task, in the manner prescribed, is a purely distal ${ }^{1}$ task and dependent upon which hand is being used for the action, controlled by the contralateral hemisphere (Jeannerod, 1988; Shafer, 1993). Asymmetry in performance was also shown between the hands in the HECP group of children but not in children with no apparent hand-eye coordination problems (Sigmundsson, 1999).

These findings, it might be speculated, suggest that insufficiency within the right hemisphere, with or without a dysfunctional corpus callosum, could be a possible factor contributing to the problems that motor-impaired children are reported to encounter in more complex everyday fine-motor skills like needlework, dressing, doing up buttons, and shoelaces etc. (for a review see Smyth, 1992) and in 'almost' every task when temporal constraints are imposed.

Analyses using lateralization-dependent variables showed a marked difference between the performances of the two hands in the HECP groups only, in favor of the right hand (preferred hand). The lateralization effect has only received minimal

\footnotetext{
${ }^{1}$ Although, the distal/proximal distinction will not be pursued here, it has recently been the focus of experimental work on motor impaired children by Sigmundsson et al., (1999b).
}

attention by research workers in this field, one of the exceptions being that of Armitage and Larkin (1993), who found a higher prevalence of crossed dominance in clumsy populations. Thus, the results of earlier studies in which scores derived from only the preferred hand or a combination of both hands was used (Laszlo \& Bairstow, 1985; Bairstow \& Laszlo, 1981; Smyth, 1991, 1994; Hulme et al., 1982a,b, 1984; Murphy \& Gliner, 1988; Williams et al., 1992; Henderson et al., 1992, Henderson et al., 1994), might, on the basis of the findings reported here, need to be qualified.

\section{CONCLUSION}

Previous research on perceptual deficits involving clumsy children have been confined to identifying deficits in particular abilities without any attempt to tease out their underlying mechanisms or causal links between underlying neural processing and behavior (Sigmundsson et al., 2002). Achieving the latter requires a processoriented approach, which attempts by appropriate experimentation to tease out the ways in which these children organize their actions in time and space. This approach, grounded in a multidisciplinary framework, has been the departure point for recent research in our group.

We suggest that the findings from our studies are behavioral manifestations of a putative neurological abnormality. This notion then raises the question of causation. The etiology of clumsiness has, generally, been couched in terms of nature versus nurture: prenatal or perinatal brain damage or limitations in postnatal experience. Dare and Gordon (1970) noted that clumsy children are often classified as having minimal cerebral dysfunction, or minimal brain damage. This view is supported by Gubbay (1975) and Hadders-Algra (2000) who argue that a continuum of neurological damage underlies motor impairment, and that an overlap 
exists between cerebral palsy (a condition manifested by poor control of movement (Stanley \& Alberman, 1984) and clumsiness. Sugden and Keogh (1990) pointed out that: 'In all cases of cerebral palsy there is a evidence of brain damage as the basic cause of the problem, although location of the damage often cannot be specified' (p. 11).

In the studies reported in the present article, the children with HECP have particular problems in using the non-preferred hand in both sensory integration and visual motor tasks (threading nuts onto a bolt). This result suggests that the default argument (minimal brain damage) pursued by Dare and Gordon (1970) and Gubbay (1975) might have to be revisited. Lack of experience may also be a reason why the functioning of these children might be deficient (Bairstow \& Laszlo, 1989; Henderson, 1992). If, for example, the children with HECP use their nonpreferred hand only minimally, then one consequence might be that the hemisphere controlling that hand will develop differentially from the hemisphere controlling the preferred hand (for overview see Bogen, 1990). Nevertheless, cause and effect, in this case, is difficult to determine: inherent processing difficulties in the hemisphere controlling the nonpreferred hand may lead to avoidance of the use of the hand wherever possible. Such avoidance, in turn, may further delay or limit the development of inter-callosal communication (Preilowski, 1972, 1990; Jeeves, 1990). Thus, a vicious circle of limited use and limited development may ensue.

\section{REFERENCES}

American Psychiatric Association. 1994. Diagnostic and Statistical Manual of Mental Disorders, $4^{\text {th }}$ Edition. Washington, DC, USA: APA; 886.

Armitage M, Larkin D. 1993. Laterality, Motor asymmetry and clumsiness. Hum Mov Sci 12: 155-177.

Bairstow PJ, Laszlo JI. 1981. Kinaesthetic sensitivity to passive movements in children and adults, and its relationship to motor development and motor control. Dev Med Child Neurol 23: 606-616.

Bairstow PJ, Laszlo JI. 1989. Deficits in the planning, control and recall of hand movements, in children with perceptuo-motor dysfunction. Br J Dev Psychol 7: 251-273.

Banich MT. 1995. Interhemispheric processing: theoretical considerations and empirical approaches. In: Davidson RJ, Hugdahl K, eds, Brain Asymmetry. Cambridge, Massachusetts, USA: MIT Press; 427-450.

Berk L. 1997. Child Development, $5^{\text {th }}$ ed. Needham Heights, Massachusetts, USA: Allyn \& Bacon Publishers.

Bogen JE. 1990. Partial hemispheric independence with the neocommissures intact. In: Trevarthen $C$, ed, Brain Circuits and Functions of the mind. New York, NY, USA: Cambridge University Press; 215-230.

Bogen JE. 1993. The Callsoal Syndromes. In: Heilman KM, Valenstein R, eds, Clinical Neuropsychology. New York, NY, USA: Oxford University Press: 337-407.

Brenner MW, Gillman S, Zangwill OL, Farrell M. 1967. Visuo-motor disability in schoolchildren. Br Med J 4: 259-262.

Dare MT, Gordon N. 1970. Clumsy children: a disorder of perception and motor organisation. Dev Med Child Neurol 12: 178-185

Dodd B, Leahy J, Hambly G. 1989. Phonological disorders in children: underlying cognitive deficits. Br J Dev Psychol 7: 55-71.

Doyle AJR, Elliott JM, Connolly KJ. 1986. Measurement of kinaesthetic sensitivity. Dev Med Child Neurol 30: 80-92.

Elliott JM, Connolly KJ, Doyle AJR. 1988. Development of kinaesthetic sensitivity and motor performance in children. Dev Med Child Neurol 30: 80-92.

Estil LB, Whiting HTA. 2002. The motor/language impairment syndrome: Direct or indirect foundations. In: Cermak SD, Larkin D, eds, Developmental Coordination Disorders. San Diego, California, USA: Singular Publishing Group.

Estil LB, Whiting HTA, Sigmundsson H, Ingvaldsen RP. 2003. Is there a common mediating factor in language and motor impairments. Infant Child Dev 12: 253-265.

Faglioni P, Basso A. 1985. Historical perspectives on neuroanatomical correlates of limb apraxia. In: Roy EA, ed, Neuropsychological Studies of 
Apraxia and Related Disorders. Amsterdam, The Netherlands: Elsevier Science Publishers B.V: 3-44.

Fleishman EA. 1966. Human abilities and the acquisition of skill. In Bilodeau EA, ed, Acquisition of Skill. New York, NY, USA: Academic Press: 147-167.

Gaddes WH. 1985. Learning Disabilities and Brain Function. A neuropsychological approach. $2^{\text {nd }}$ Edition. New York, NY, USA: Springer-Verlag.

Galin D, Diamond R, Herron J. 1977. Development of crossed and uncrossed tactile localisation on the fingers. Brain Lang 4: 588-590.

Geschwind N. 1975. The apraxias: Neural mechanisms of disorders of learned movement, Am Sci 63: 188-195.

Gordon N, McKinley I. 1980. Helping Clumsy Children. Edinburgh, Scotland: Churchill Livingstone.

Gubbay SS, Ellis T, Walton JN, Court SDM. 1965. Clumsy children: A study of apraxia and agnosic deficits in 21 children. Brain 88: 295-312.

Gubbay SS. 1975. The clumsy child: A study of Developmental and Agnosic Ataxia. London, UK: Saunders.

Gubbay SS. 1978. The management of developmental apraxia. Dev Med Child Neurol 20: 643-646.

Hadders-Algra M. 2000. The clumsy child-at the border of cerebral palsy? In: Velcikovic Peret M, Neville B, eds, Cerebral Palsy. Amsterdam, The Netherlands: Elsevier Science.

Heilman KM, Rothi LJG. 1993. Apraxia. In: Heilman KM, Valenstein R, eds, Clinical Neuropsychology $3^{\text {rd }}$ Edition. New York, NY, USA: Oxford University Press: 141-163.

Henderson SE, Hall D. 1982. Concomitants of clumsiness in young schoolchildren. Dev Med Child Neurol 24: 448-460.

Henderson SE. 1992. Clumsiness or developmental co-ordination disorder: a neglected handicap. Curr Paediatr 2: 158-162.

Henderson L, Rose P, Henderson SE. 1992. Reaction time and movement time in children with a Developmental Coordination Disorder. J Child Psychol Psychiat 33: 895-905.

Henderson SE, Sugden D. 1992. The movement assessment battery for children. Kent, UK: The Psychological Corporation; 240.

Henderson SE. 1993. Motor Development and minor handicap. In: Kalverboer AF, Hopkins B, Geuze $\mathrm{RH}$, eds, Motor development in early and later childhood. Longitudinal approaches. European
Network on Longitudinal Studies on Individual Development (ENLS). Cambridge, UK: Cambridge University Press.

Henderson SE, Barnett A, Henderson L. 1994. Visuospatial Difficulties and Clumsiness: On the Interpretation of Conjoined Deficits. J Child Psychol Psychiat 35: 961-969.

Hofsten C von, Rösblad B. 1988. The integration of sensory information in the development of precise manual pointing. Neuropsychologia 26: 805-821.

Hulme C, Biggerstaff A, Moran G, McKinley I. 1982a. Visual, kinaesthetic and cross-modal judgements of length by normal and clumsy children. Dev Med Child Neurol 24: 461-71.

Hulme C, Smart A, Moran G. 1982b. Visual perceptual deficits in clumsy children. Neuropsychologia 20: 475-481.

Hulme C, Smart A, Moran G, McKinley I. 1984. Visual, kinaesthetic and cross-modal judgments of length by clumsy children: a comparison with young normal children. Child care Health Dev 10: 117-125.

Hulme C, Lord R. 1986. Clumsy children-a review of recent research. Child Care Health Dev 12: 257-269. [Review ]

Jeannerod M. 1988. The Neural and Behavioral Organisation of Goal-Directed Movements. Oxford, UK: Oxford University Press.

Jeeves MA. 1990. Agenesis of the corpus callosum. In: Nebes RD, S. Corkin S, eds, Handbook of Neuropsychology. Amsterdam, The Netherlands: Elsevier Science Publishers B.V: 99-114.

Jongmans M. 1989. The relationship between perception and action in manual control of children with specific movement difficulties. Faculty of Human Movement Sciences. Free University Amsterdam, The Netherlands. [Unpublished study]

Kalat JW. 1995. Biological Psychology. Pacific Grove, California: USA: Brooks/Cole Publishing Co.

Keogh JF, Sugden DA, Reynard CL, Calkins JA. 1979. Identification of clumsy children: Comparisons and comments. J Hum Mov Stud 5: 32-41.

Laszlo JI, Bairstow PJ. 1985. Perceptual motor behavior: Developmental assessment and therapy. London, UK: Holt, Rinehart \& Winston.

Laszlo JI, Bairstow PJ, Bartrip J, Rolfe UT. 1988 Clumsiness or perceptuo-motor dysfunction. In: Colley AM, Beech JR, eds, Cognition and Action in Skilled Behavior. Amsterdam, the Netherlands: Elsevier Science Publishers B.V. 
Laszlo JI. 1990. Child perceptuo-motor development: Normal and abnormal development of skilled behavior. In: Hauert CA, ed, Developmental Psychology: Cognitive, Perceptuo-motor and Neurophysiological Perspective. Amsterdam, the Netherlands: North-Holland: 273-308.

Laszlo JI, Sainsbury KM. 1993. Perceptual-motor development and prevention of clumsiness. Psychol Res 55: 167-174.

Lee DN, Daniel BM, Turnball J, Cook ML. 1990. Basic perceptuo-motor dysfunctions in cerebral palsy. In: Jennerod $\mathrm{M}$, ed, Attention and performance XIII: Motor representation and control. Hillsdale, New Jersey, USA: Erlbaum Associates: 593-603.

Lee DN, Hofsten C von, Cotton E. 1997. Perception in Action Approach to Cerebral Palsy. In: Connolly KJ, Forssberg H, eds, Neurophysiology and Neuropsychology of Motor Development. London, UK: Mac Keith Press.

Mæland AF. 1992. Identification of children with motor coordination problems. Adapt Phys Act Quart 9: 330-342.

Morris PR, Whiting HTA. 1971. Motor impairment and compensatory education. Philadelphia, Pennsylvania, USA: G. Bell and sons, Ltd.

Murphy JB, Gliner JA. 1988. Visual and motor sequencing in normal and clumsy children. Occup Ther J Res 8; 89-101.

Nickish A. 1998. Motorische Störungen bei Kindern mit verzögerter Sprachentwicklung. Folia Phoniatrica 40: 147-152.

O'Leary DS. 1980. A developmental study of interhemispheric transfer in children aged five to ten. Child Dev 51: 743-750.

Orton ST. 1937. Reading, writing and speech problems in children. New York, NY, USA: Norton.

Oseretsky N.I. 1923. A metric scale for studying the motor capacity of children. [In Russian]

Paul R, Cohen DJ, Caparulo BK. 1983. A longitudinal study of patients with severe developmental disorders of language learning. J Am Acad Child Psychiatry 22: 525-534.

Powell RP, Bishop DVM. 1992. Clumsiness and perceptual problems in children with specific language impairment. Dev Med Child Neurol 34: 755-765.

Preilowski B. 1972. Possible contribution of the anterior forebrain commissures to bilateral co-ordination. Neuropsychologia 10: 267-77.

Preilowski B. 1990. Intermanual transfer, interhemi- spheric interaction, and handedness in man and monkeys. In: Trevarthen $\mathrm{C}$, ed, Brain Circuits and Functions of the Mind. New York, NY, USA Cambridge University Press; 160-180.

Quinn K, Geffen G. 1986. The development of tactile transfer of information. Neuropsychologia 24: 793-804.

Rintala $\mathrm{P}$, Pienimäki $\mathrm{K}$, Ahonen $\mathrm{T}$, Cantell $\mathrm{M}$, Kooistra L. 1998. The effects of a psychomotor training programme on motor skill development in children with developmental language disorders. Hum Mov Sci 17: 721-737.

Rösblad B, Hofsten C von. 1992. Perceptual control of manual pointing in children with motor impairments. Physiother Theory Pract 8: 223-233.

Rutter M. 1978. Prevalence and types of dyslexia. In Benton AL, Pearl D, eds, Dyslexia. An Appraisal of Current Knowledge. New York, NY, USA: Oxford University Press.

Sandström CI. 1953. Sex differences in localisation and orientation. Acta Psychol 9: 82-96.

Sandström CI, Lundberg I. 1956. A genetic approach to sex differences in localisation. Acta Psychol 12: 247-253.

Shafer DD. 1993. Patterns of handedness: Comparative study of nursery school children and captive gorillas. In: Ward JP, Hopkins WD, eds, Primate Laterality: Current Behavioral Evidence of Primate Asymmetries. New York, NY, USA: Springer Verlag: 267-283.

Sherrington CS. 1906. The Integrative Action of the Nervous System. New Haven, Connecticut, USA: Yale University Press.

Sigmundsson H, Ingvaldsen RP, Whiting HTA. 1997a. Inter-and intra-sensory modality matching in children with hand-eye co-ordination problems. Exp Brain Res 114: 492-499.

Sigmundsson H, Ingvaldsen RP, Whiting HTA. 1997b. Inter- and intra-sensory modality matching in children with hand-eye co-ordination problems: exploring the developmental lag hypothesis. Dev Med Child Neurol 12: 790-796.

Sigmundsson H. 1999. Inter-modal matching and bimanual co-ordination in children with hand-eye coordination problems. Nordisk Fysioterapi 3: 55-64.

Sigmundsson H, Whiting HTA, Ingvaldsen RP. 1999a. Putting your foot in it! A window into clumsy behavior. Behav Brain Res 102: 131-138.

Sigmundsson H, Whiting HTA, Ingvaldsen RP. 1999b. Proximal versus distal control in proprioceptively 
guided movements of motor-impaired children. Behav Brain Res 106: 47-54.

Sigmundsson H, Whiting, HTA, Loftesnes JM. 2000. Development of proprioceptive sensitivity. Exp Brain Res 135: 348-352.

Sigmundsson H, Whiting HTA. 2002. Hand preference in children with developmental co-ordination disorders: cause and effect? Brain Cogn 49: 45-53.

Sigmundsson H, Hansen PC, Talcott JB. 2003. Do 'clumsy' children have visual deficits? Behav Brain Res 139: 123-129.

Smyth TR. 1991. Abnormal clumsiness in children: A programming defect? Child Care Health Dev 17: 283-294.

Smyth TR. 1992. Impaired motor skill (clumsiness) in otherwise normal children: a review. Child Care Health Dev 18: 283-300.

Smyth TR. 1994. Clumsiness in children: a defect of kinaesthetic perception? Child Care Health Dev 20: $27-36$.

Sperry, R.W. 1974. Lateral specialisation in the surgically separated hemispheres. In Schmitt FO, Worden FG, eds, The Neurosciences: Third study program. Cambridge, Massachusetts, USA: MIT Press; 5-19.

Søvik N, Mæland AF. 1986. Children with motor problems ("clumsy children"). Scand J Edu Res 30: 39-53.

Stanley F, Alberman E. 1984. Birth weight, gestational age and the cerebral palsies. Clinics in Developmental Medicine 87: 57-68.

Stein JF. 1994. Developmental dyslexia, neural timing and hemispheric lateralisation. Int $\mathrm{J}$ Psychophysiol 18: 241-249.

Stevenson J. 1984. Predictive value of speech and language screening. Dev Med Child Neurol 26: 528-538.

Stott DH.1966. A general test of motor impairment for children. Dev Med Child Neurol 8: 523-31.

Sugden D, Wann C. 1988. Kinaesthesis and motor impairment in children with moderate learning difficulties. Br J Ed Psychol 57: 225-36.

Sugden DA, Keogh JF. 1990. Problems in Movement Skill Development. Columbia, South Carolina, USA: University of South Carolina Press.

Trevarthen C. 1974. Cerebral embryology and the split brain. In: Kinsbourne M, Smith WL, eds, Hemispheric disconnection and cerebral function. Springfield, Illinois, USA: Charles C. Thomas; 208-236.

Waal A., Sigmundsson H, Whiting HTA. 2000. Differential contributions of the two hemispheres in intra-modal proprioceptive sensory matching in 7-10 year-old boys. Behav Brain Res 114: 17-22.

Walton JN, Ellis E, Court S. 1962. Clumsy Children: Developmental apraxia and agnosia. Brain 85: 603-612.

Williams HG, Wollacott MH, Ivry R. 1992. Timing and Motor Control in Clumsy Children. J Motor Behav 24: 165-172.

Wolff PH, Melngailis I, Obregon M, Bedrosian M. 1995. Family Patterns of developmental dyslexia. 2. Behavioral phenotypes. Am J Med Genetics. 60: 494-505.

Yakolev PI, Lecours AR. 1967. The myelogenetic cycles of regional maturation of the brain. In: Minkowski A, ed, Regional Development of the Brain in Early Life. Philadelphia, Pennsylvania, USA: Davis. 

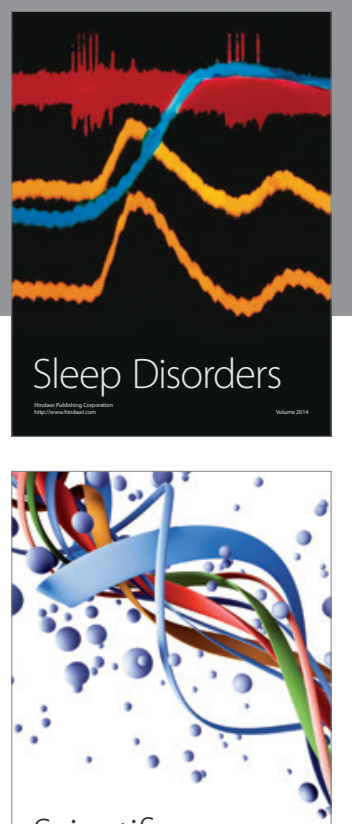

Scientifica
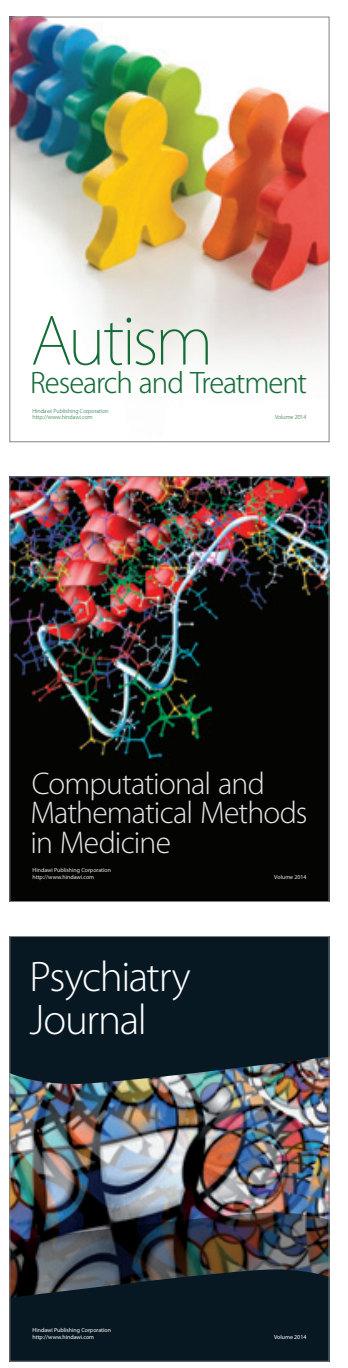
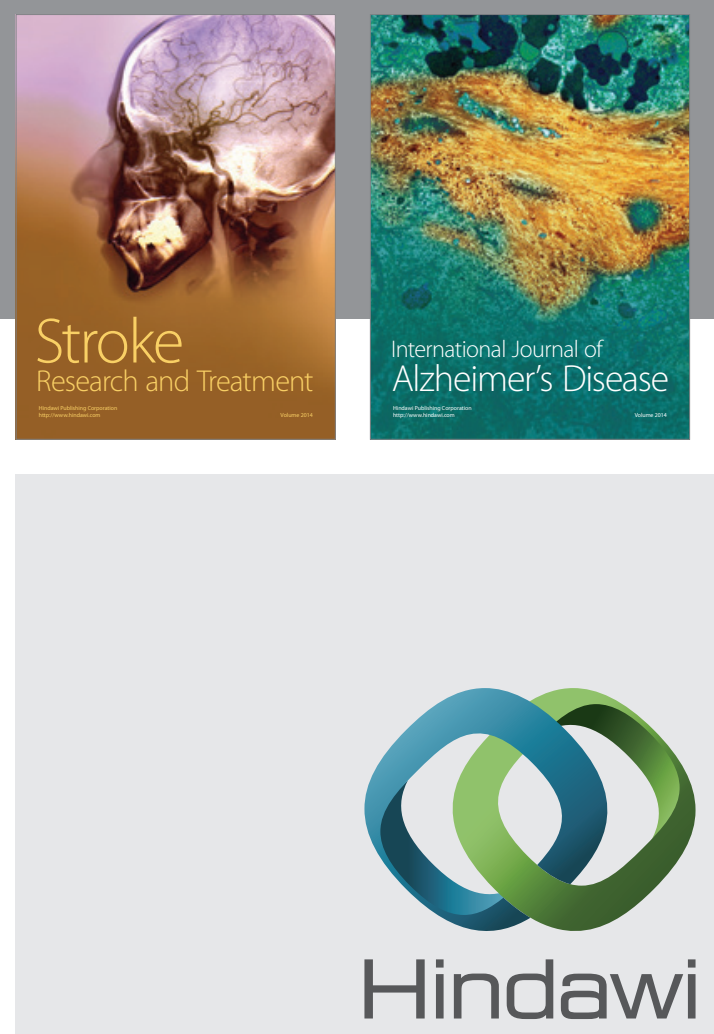

Submit your manuscripts at

http://www.hindawi.com
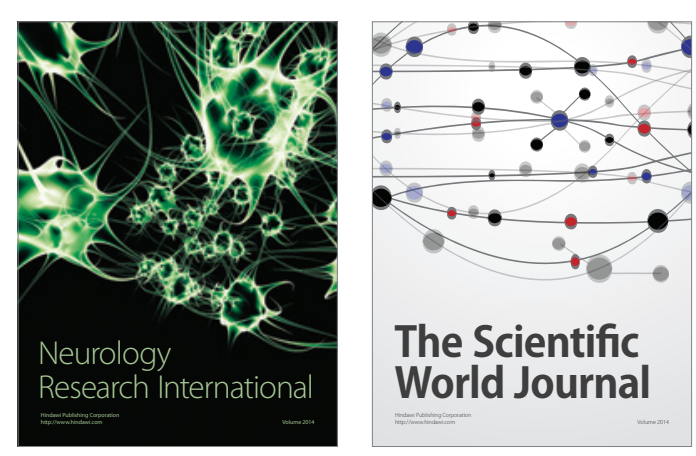

The Scientific World Journal

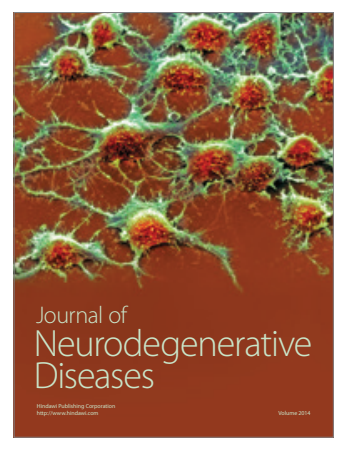

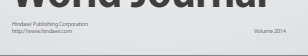

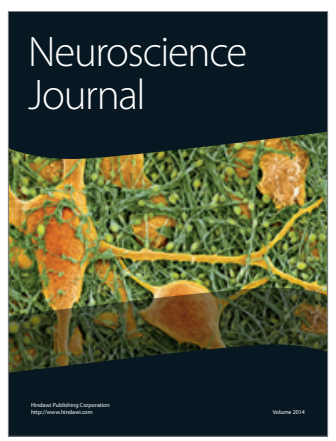

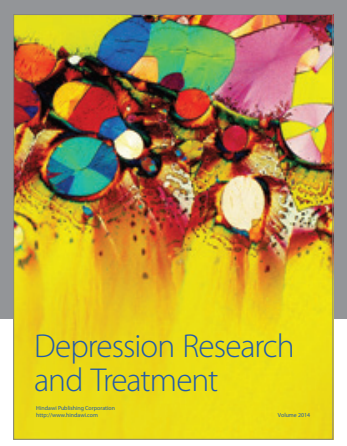
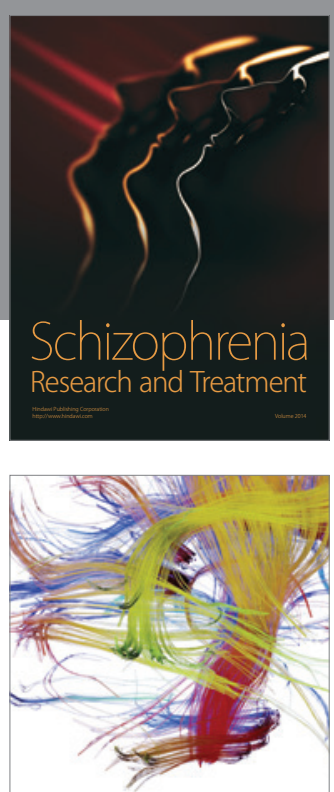

Brain Science

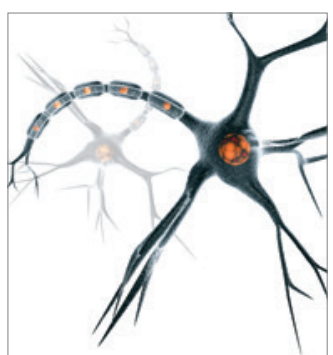

Neural Plasticity
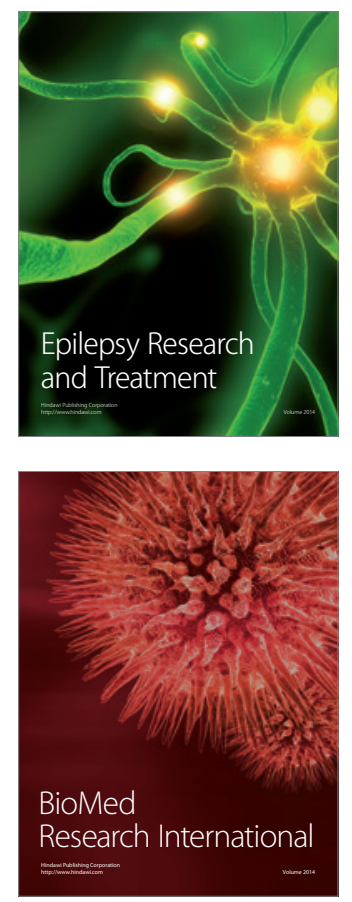

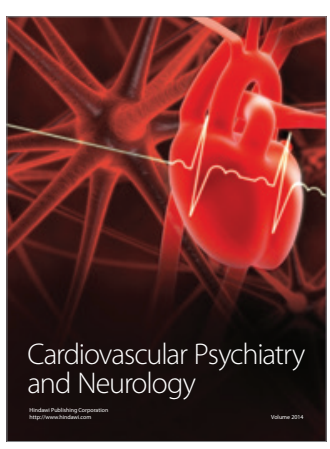

Parkinson's

Disease
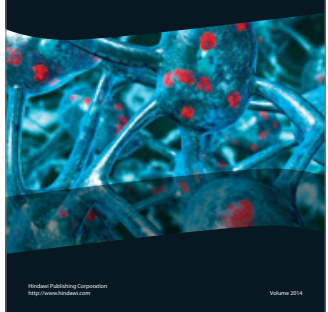